\title{
Prevalence and Perceptions in the Management of Buruli Ulcer in Oguta Local Government Area of Imo State, Nigeria
}

\author{
Udujih. O. $G^{1} \mid$ Udujih, H. I. ${ }^{2^{*}} \mid$ Okeke J. A. $^{3} \mid$ Iwuala C. C $^{1} \mid$ Nwosu, H. ${ }^{1} \mid$ Okolo, N. ${ }^{1}$
}

| Dozie, U.W. ${ }^{1}$

${ }^{1} 1$.Department of Public Health, School of Health Technology, Federal University of Technology Owerri

22.Department of Medical Laboratory Science, Faculty of Health Sciences, Imo State University Owerri

${ }^{3} 3$.Leprosy, Tuberculosis And Buruli Ulcer Unit,Ministry of Health Imo State, Nigeria

\begin{abstract}
A study was carried out in Oguta One community of Oguta Local Government Area to determine the prevalence and perceptions in the management of Buruli Ulcer among residents. Interviews and structured questionnaire were used for case finding and to obtained information on knowledge and perception. Physical examination and standard bacteriological techniques were used to confirm BU cases. The result showed a prevalence of $0.2 \%$ out of the 356 participants. There was knowledge of the disease but poor understanding of its cause and mostly perceived to be a supernatural disease by which treatment could be sought from herbal homes and churches. Age, Education and occupation had strong association $(\mathrm{P}<0.05)$ with the knowledge of Buruli ulcer with the exception of sex $(\mathrm{P}>0.05)$. From these findings, it is evident that a more robust case finding is necessary in the country as many cases would be missed without the inclusion of herbal/tradomedical homes and churches in control programs especially as regards education on the true cause of BU disease.

Keywords: Buruli Ulcer, Imo State, Nigeria
\end{abstract}

\section{1 | INTRODUCTION:}

$\mathrm{B}$ uruli ulcer is a devastating infectious disease caused by Mycobacterium ulcerans. It is named after Buruli County (now called Nakasongola District) located near the Nile River in Uganda, where in 1961 the first large number of cases was reported (WHO, 2000). Mycobacterium ulcerans infection was first described in 1987 by Sir Alfred Cook, a missionary doctor in the Buruli County in Uganda (WHO, 2013). The causative organism is from the family of bacteria which causes tuberculosis and leprosy but Buruli ulcer has received less attention than these diseases (WHO, 2000; Kargbo-Labour, 2010).

Supplementary information The online version of this article (https://doi.org/10.15520/mcrr.v3i9.141) contains supplementary material, which is available to authorized users.

Corresponding Author: Udujih, H. I.

2.Department of Medical Laboratory Science, Faculty of Health Sciences, Imo State University Owerri 
Scarring, contractures, and lymphedema may result after healing of Buruli ulcers. Scarring and contractures can have significant social, psychological, physical, and economic impact on patients. Osteomyelitis, metastatic lesions, and secondary infections are additional potential complications. Squamous cell carcinomas have been reported in $\mathrm{Bu}-$ ruli ulcers (Minutilli et al., 2007). Secondary infections are common with Buruli ulcers, as clean water sources for wound care are frequently limited. A staggering $23 \%$ of patients diagnosed with Buruli ulcers in Ghana between August 2010 and December 2012 were coinfected with Mansonella perstans nematodes (Phillips et al., 2014). The oedematous form of infection produces diffuse swelling of a limb, which, unlike the papule or nodule, can be painful and accompanied by low-grade fever, Infection may follow physical trauma, often minor trauma such as a small scratch (Sizaire et al., 2006).

The natural reservoir and mode of transmission of the infection remain largely obscure and might differ between endemic foci around the world. However, skin injury and insect bites have been proposed as modes of transmission (Nienhuis et al., 2010). In March 2008, researchers announced the first isolation of M. ulcerans from the environment (Portaels et al., 2008). This suggested that the disease might be transmitted via contact with the environment rather than person to person. The entire genome of $M$. ulcerans has been sequenced (Yoshida et al., 2016).

Community perception and knowledge about diseases have a negative impact on the health-seeking behaviour of patients. For this reason, all information on the socio-cultural factors (perception, knowledge and culture of wounds about the disease) is highly relevant for a better understanding of the disease as a whole and to serve as a useful material for future control programs. Despite increased geographical spread of Buruli ulcer in sub-Saharan Africa especially in West Africa, there is dearth of information on epidemiology of the disease in Nigeria when compared with some of West African countries: Ghana, Benin Republic, Togo, and Cameroon.

The epidemiology of BU is very important to prevent and control the disease however the unraveled mode of transmission hampers efforts. Consequently, information on the perception of BU disease among the most predisposed populace is very vital in achieving this. In addition, finding out the prevalence of $\mathrm{BU}$ which is uncertain in most endemic countries, encouraging early reporting by affected people and ensuring prompt treatment thereby preventing the extensive devastating effects of BU will go a long way in its control. The issues raised above informed the choice of the study which aims at evaluating the perception and practices in the management of Buruli ulcer in Imo state.

\section{2 | METHODS:}

\section{Study Area}

This study was undertaken in Imo state, which is one of the 36 states of Nigeria. Owerri is its capital and among the largest town in the State. Its other notable towns are Orlu, Obowo, Oguta, Mbaise and Okigwe. Located in the south- eastern region of Nigeria, it occupies the area between the lower River Niger and the upper and middle Imo River. Imo State is bordered by Abia State on the east, River Niger and Delta State to the west, Anambra State on the North and Rivers State to the south. The state lies within latitudes $4^{\circ} 45^{\prime} \mathrm{N}$ and $7^{\circ} 15^{\prime} \mathrm{N}$, and longitude $6^{\circ} 50^{\prime} \mathrm{N}$ and $7^{\circ} 25^{\prime} \mathrm{E}$ with an area of about $5,100 \mathrm{sq}$ $\mathrm{km}$. The economy of the state depends primarily on agriculture and commerce. Imo State is currently consisted of 27 Local Government Areas, Oguta Local Government Area was purposively selected for this study based on presence of a lake in one of the communities

\section{Study Design/ Study Population}

The study lasted from August to September 2019. Data was obtained by a descriptive observational study involving cross-sectional household survey which adopted the administration of structured questionnaire to consenting respondents given during an interview in the Oguta One community in the local government area. Information gathered were, sociodemographic variables including local government area, gender, level of education, age, occupation and religion.

A total of 356 respondents from the three local government areas participated in the study. Formal 
consent was sought and obtained from the concerned authorities, Individual consent was sought from the subjects and those who gave their consent were recruited for the study.

The perception of respondents was based on responses of the respondents to questions relating to awareness on BU, its causative agent, forms of BU presentation, possible ways of exposure, treatment, methods/modes of management and attitude towards BU patients. Prevalence of BU was obtained by identification of active debilitating ulcer and confirmation of microscopic Mycobacterium rods after Ziehl Neelson Stain of wound swabs from the ulcer. Histories of debilitating ulcer within the past 24 months were also recorded.

Data was analyzed using software statistical package for social sciences (SPSS) version 20.0. The results were expressed as mean and standard deviation (mean $\pm \mathrm{SD}$ ). The difference in mean values between groups was assessed by student t-test. Tests with a probability value of $\mathrm{P}<0.05$ were considered statistically significant.

\section{3 | RESULTS AND ANALYSIS:}

\section{Demographic characteristics of participants}

Out of the 356 participants, majority (28.4\%) fell within 34 to 41 years and $27.0 \%$ fell within age bracket of 26-33. About $23.6 \%$ fell within $18-25$ years, $11.5 \%$ fell within $42-49$ years and the last proportion $(9.5 \%)$ of the respondents fell within age bracket 50 years and above. A greater proportion $(58.4 \%)$ of the respondents in the study area was females while $41.6 \%$ were males. Majority (43.3\%) of the respondents had primary Education and about $22.7 \%$ had no formal Education at all. Also, 15.3\% had secondary school Education while $4.7 \%$ and $3.3 \%$ had both tertiary and post graduate Education. Majority (84.7\%) of the respondent came from Christian families while about $7.7 \%$ were traditionalists, 5.5\% were Islamic and a lower proportion $(3.3 \%)$ was pagans. A greater proportion $(30.0 \%)$ of the respondents was civil servants, about $24.3 \%$ were engaged in other businesses, and $14.7 \%$ of the respondents were farmers. Hence, about $12.7 \%$ were unemployed and 9.0\% were hunters while smaller proportions $(3.3 \%)$ were apprentices.

\section{Prevalence and knowledge of Buruli Ulcer in Oguta Local Government Area of Imo State}

There was only one active case of Buruli ulcer out of the 356 participants in the study area. Hence, the prevalence of BU recorded was $(0.28 \%)$. The only case was a female in the age bracket $42-49$ years.

The respondents' knowledge regarding Buruli ulcer is presented in Table 1 . One hundred and sixty nine $(47.5 \%)$ of the respondents responded affirmatively to knowing what Buruli ulcer is, while majority of the respondents $187(52.5 \%)$ had no clue. Those who had knowledge of the disease 169 (47.5\%) were quizzed further on the definitions of Buruli ulcer. Seventy two (42.6\%) affirmed that it is a chronic debilitating ulcer (difficult to heal wound) on the skin or soft tissue while $46(27.2 \%)$ refuted this definition. On the causes of Buruli ulcer, greater proportion of the respondents $121(34.0 \%)$ asserted that Buruli ulcer is caused by witchcraft whereas 89 (25.9\%) affirmed that it was caused by a bacterium. However, 113 (31.7\%) of the respondents mentioned other presumed causes of Buruli ulcer. Regarding the treatment of Buruli ulcer, majority of the respondents 141 (39.6\%) did not know that Buruli ulcer was treatable. This was closely followed by $129(36.2 \%)$ of the respondents who averred that Buruli ulcer is treatable. However, $86(24.2 \%)$ of the respondents were not sure if Buruli ulcer was treatable or not.

The 3 variables (Age, Education and occupation) had strong association with the knowledge of $\mathrm{Bu}-$ ruli ulcer with the exception of $\operatorname{sex}\left(\mathrm{X}^{2}=21.338\right.$, $35 \%, \mathrm{P}=0.069)$. This means that age $\left(\mathrm{X}^{2}=48.295\right.$, $25 \%, \mathrm{P}=0.000$ ) had been strongly associated with the knowledge of Buruli ulcer. Education was highly associated $\left(X^{2}=30.159,19 \%, P=0.004\right)$ and occupation $\left(\mathrm{X}^{2}=33.613,21 \%, \mathrm{P}=0.001\right)$ was highly associated with the level of respondents' knowledge.

\section{Perception of Respondents Regarding Buruli Ul- cer}

Out of the 356 participants, 118 (33.1\%) respondents perceived Buruli ulcer to be difficult to heal because it was caused by witches while $105(29.5 \%)$ presumed that the difficulty experienced in the healing 
PREVALENCE AND PERCEPTIONS IN THE MANAGEMENT OF BURULI ULCER IN OGUTA LOCAL GOVERNMENT AREA OF IMO STATE, NIGERIA

TABLE 1: FrequencyDistribution of Respondents Knowledge on Buruli Ulcer

$\begin{array}{lll}\text { Variables } & \begin{array}{l}\text { Frequency } \\ (356)\end{array} & \begin{array}{l}\text { Percentage } \\ \text { (\%) }\end{array} \\ \text { Knowledge of Buruli ulcer } & 169 & 47.5 \\ \text { Yes } & 187 & 52.5 \\ \text { No } & & \\ \text { Knowledge on definition of Buruli Ulcer (n=169) } & \\ \text { A chronic deliberating ulcer (difficult to heal wound) on the skin or soft } & \\ \text { tissues } & 72 & 42.6 \\ \text { Yes } & 46 & 27.2 \\ \text { No } & 51 & 30.2 \\ \text { Not sure } & & \\ \text { A witchcraft projected sickness } & 112 & 66.3 \\ \text { Yes } & 35 & 20.7 \\ \text { No } & 22 & 13.0 \\ \text { Not sure } & & \\ \text { Knowledge on what causes Buruli ulcer } & 89 & 25.0 \\ \text { A bacterium } & 121 & 34.0 \\ \text { Witchcraft } & 9.3 \\ \text { Drinking bad water } & 33 & 31.7 \\ \text { Others } & 113 & \\ \text { Knowledge on the possibility of treating Buruli ulcer } & & 36.2 \\ \text { Yes } & 129 & 39.6 \\ \text { No } & 141 & 24.2 \\ \text { Not sure } & 86 & \end{array}$

of Buruli ulcer is because of perceived spiritual enemies. However, only 79 (22.5\%) of the respondents rightly assumed that the reason for the difficulty in the healing of Buruli ulcer was because most Buruli ulcer patients do not seek treatment for Buruli ulcer. It was evident that more participants were of the view that the best places to get treatment for Buruli ulcer was in the church, 87 (24.4\%) believe that hospital was the best place to get treatment for Buruli ulcer. Regarding associating with Buruli ulcer patients, 115 $(43.5 \%)$ of the respondents said they would associate with Buruli ulcer patients. However, a larger proportion of the respondents $201(56.5 \%)$ answered no to the same question. Ninety six $(27.0 \%)$ participants and $81(22.8 \%)$ of the respondents presumed that $\mathrm{Bu}-$ ruli ulcer could be contracted by stepping on poison and through witchcraft activities respectively while $62(17.5 \%)$ of the respondents asserted that Buruli ulcer could be contracted by swimming in a dirty pond/ river. Table 2

\section{Practices Regarding Buruli Ulcer}

A larger proportion of the participants out of the 356 respondents, $(38.89 \%)$ said they would first seek treatment from churches/ spiritual homes when they notice they had Buruli ulcer. This was followed by $(30.55 \%)$ of the participants who would first seek treatment from herbal homes while only (19.44\%) of the patients would first seek treatment from hospitals. Regarding the kind of medication used for treatment, more of the participants (44.44\%) affirm they would use orthodox medication for treatment; Fourteen (38.89\%) participants would use prayers and spiritual materials for treatment while the rest $(16.67 \%)$ had no clue.

\section{4 | DISCUSSION:}

Information on the knowledge and perception of $\mathrm{Bu}$ ruli Ulcer disease among the most predisposed popu- 
MANUSCRIPT CENTRAL

TABLE 2: FrequencyDistribution of Respondents Perception Regarding Buruli Ulcer

\begin{tabular}{lll} 
Variable & Frequency (356) & Percentage (\%) \\
why Buruli ulcer is difficult to heal & & \\
Because it is caused by witches & 118 & 33.1 \\
Because it is caused by enemies & 105 & 29.5 \\
Because most victims do not seek treatment on time & 79 & 22.2 \\
Others & 54 & 15.2 \\
\hline Participants perception on where best to get treatment & & \\
Hospital & 87 & 24.4 \\
Chemist & 41 & 11.5 \\
Church & 126 & 35.5 \\
\hline Local Herbalist & 102 & 28.7 \\
Would you associate with Buruli ulcer patient & & \\
Yes & 155 & 43.5 \\
No & 201 & 56.5 \\
\hline Perception regarding how Buruli ulcer can be contracted & & \\
By swimming in a dirty pond/ river & 62 & 17.4 \\
By stepping on the buruli ulcer poison & 96 & 27.0 \\
\hline Through the evil works of the devil & 76 & 21.3 \\
\hline Through witchcraft activities & 81 & 22.8 \\
Others & 41 & 11.5 \\
\hline
\end{tabular}

lace is very vital in achieving control or eradication. The epidemiology of the disease is also necessary to elucidate the transmission cycle, discover predisposing factors and pinpoint areas to apply intervention. A Buruli Ulcer prevalence of $10.11 \%$ was recorded in this study. This is higher than the 18.7per100, 000 prevalence recorded by Ukwuaja et al (2016) among children and adults in three rural districts of Ogoja territory of Cross River State, Nigeria. In endemic communities in Nigeria, the number of BU cases is grossly underestimated (Ukwaja et al., 2016). It is possible that several cases would be missed where there is no deliberate efforts to engage communities to identify and notify the appropriate health ministry in Imo State. A step up of the BU case finding in communities where standard reporting has previously identified cases should also be implemented.

In this study, majority of the respondents were knowledgeable about the disease referred as "Ochaere" in the native dialect. However, the knowledge on true cause and treatment was poor. About a quarter $(25.9 \%)$ of the participants rightly knows that Buruli ulcer is caused by bacteria. A lot more of the participants presume it was caused by witchcraft (34.0\%) and drinking bad water $(9.3 \%)$ while. These findings corroborate that of Ahorlu, (2013) on community knowledge and perception of Buruli ulcer in Ogun state, Nigeria. Age, Education and occupation had strong association $(\mathrm{P}<0.05)$ with the knowledge of Buruli ulcer with the exception of $\operatorname{sex}(\mathrm{P}=0.069)$.

The respondents' perception regarding Buruli ulcer, as revealed in this study, was not encouraging. This is evident as majority (39.6\%) of the respondents erroneously thinks that Buruli ulcer is difficult to heal because it was caused by witches or perceived spiritual enemies. In addition, more than half of the respondents, believed that the best place to get treatment or help for Buruli ulcer is from the church (35.5\%)or from a local herbalist $(28.7 \%)$. Only a few $(24,4 \%)$ of the participants saw the hospitals as the best place to get treatment. These findings concur with that of Friedman et. al., (2013) on the knowledge, attitude and practice on the mode of transmission, prevention and treatment of Buruli ulcer in $\mathrm{Ga}$ West District, Ghana as well that of Ahorlu (2013) where both revealed that $71.8 \%$ and $57.6 \%$ of respondents in their respective studies favor traditional 
treatment or herbal remedy as the best treatment for Buruli ulcer. Furthermore, it was observed from this study that Buruli ulcer attract a measure of stigma. This is evidenced as m0re than half $(58.33 \%)$ of the cases felt stigmatized. This finding consents to that of Friedman et al., (2013) whose findings also depict a negative attitude towards Buruli ulcer sufferers that has social implications.

The general poor attitude shown by respondents regarding Buruli ulcer in this study is in tandem with the study on perception and incidence of Buruli ulcer in Ogun state, South west Nigeria by Phillips et al., (2014) who revealed that $54.7 \%$ of the total respondents had poor level of BU perception

Elucidated in this study is the respondents practices regarding Buruli ulcer which revealed that most of the Buruli ulcer patients' first point of call for treatment was a church or a herbal home. The number of participants patronizing hospitals for treatment probably increased subsequently, after the deterioration of condition. This finding agrees with that of Friedman et al (2013) which showed that only $22.8 \%$ of respondents thought Buruli ulcer sufferers should seek help at the hospital or local doctor/ nurse as the first option.

\section{5 | CONCLUSION:}

Globally, Buruli ulcer disease has assumed a great health concern because of the severe pain, disfigurement and harsh economic burden on affected people. Population studies are very important in understanding peculiar diseases inherent in population information on such diseases from the affected people offers very important direction mostly to researchers. Ascertaining the perception of people from this study on $\mathrm{BU}$ has provided a vital overview on the knowledge of BU exhibited by respondents in these Local Government Areas, which were fundamentally wrong. The participants in this study did not believe that BU is treatable; many believed that witchcraft was the cause and many more did not know the treatment. This study has thrown more light on the epidemiology of BU in the study area and will subsequently spur intervention projects to encourage access to medical help to forestall extensive consequences.

\section{6 | REFERENCES:}

Ahorlu, C. K., Koka, E., Yeboah-Manu, D., Lamptey, I., \& Ampadu, E. (2013). Enhancing Buruli Ulcer Control in Ghana through Social Interventions: A Case Study from the Obom SubDistrict. BMC Public Health. 13(4): 50-59.

Friedman, N.D., Athan, E., Hughes, A.J., Khajehnoori, M., McDonald, A., Callan. (2013). Mycobacterium ulcerans disease: experience with primary oral medical therapy in an Australian cohort. PLoS Neglected Tropical Disease. 7(7): 43-47

Kargbo-Labour, I. J. (2010). Community Perception and Knowledge of Buruli Ulcer in the Ga West Municipality Area . Ghana: University of Ghana. 21(12): 56-60

Minutilli, E., Orefici, G., Pardini, M. (2007). Squamous cell carcinoma secondary to buruli ulcer. Dermatological Surgery. 33(7):872-875.

Nienhuis, W.A., Stienstra, Y., Thompson, W.A. (2010). Antimicrobial treatment for early, limited Mycobacterium ulcerans infection: a randomised controlled trial. Lancet. 375(97): 664-672.

Phillips, R.O., Frimpong, M., Sarfo, F.S., Kretschmer, B., Beissner, M., Debrah, A. (2014) Infection with Mansonella perstans Nematodes in Buruli Ulcer Patients, Ghana. Emergent of Infectious Disease. 20 (6):1000-1003.

Portaels, F., Meyers, W.M., Ablordey, A., Castro, A.G., Chemlal, K., de Rijk, P., Elsen, P., Fissette, K., Fraga, A.G., Lee, R., Mahrous, E., Small, P.L., Stragier, P., Torrado, E., Van Aerde, A., Silva, M.T., Pedrosa, J. (2008). "First Cultivation and Characterization of Mycobacterium ulcerans from the Environment". PLoS Neglect of Tropical Disease. 2 (3): 1718.

Sizaire, V., Nackers, F., Comte, E., Portaels. F. (2006). "Mycobacterium ulcerans infection: control, diagnosis, and treatment". Lancet of Infectious Diseases. 6(5): 288-296.

Ukwaja K.N., Meka, A.O., Ntana, K (2016). Buruli ulcer in nigeria: results of a pilot case study in three rural districts. Infectious Diseases Of Poverty, 5(39) World Health Organization, WHO. (2000). Buruli Ulcer: Mycobacterium ulcerans Infection. World 


\section{MANUSCRIPT CENTRAL}

Health Organization.

World Health Organization. (2013). Treatment of mycobaterium ulcerans disease (Buruli ulcer): guidance for health workers:. World Health Organization.

Yoshida, M., Nakanaga, K., Ogura, Y., Toyoda, A., Ooka, T., Kazumi, Y., Mitarai, S, Ishii, N., Hayashi, T., Hoshino, Y. (2016). "Complete Genome Sequence of Mycobacterium ulcerans subsp. shin- shuense”. Genome Announc. 4(5):43-54

How to cite this article: O. G U., H. I. U., J. A. O., C. C I., H. N., N. O., U.W. D. Prevalence and Perceptions in the Management of Buruli Ulcer in Oguta Local Government Area of Imo State, Nigeria. Journal of Medical Care Research and Review. 2020;437-443. https://doi .org/10.15520/mcrr.v3i9.141 